\title{
O NOVO CÓDIGO DE ÉTICA E DISCIPLINA DA OAB - REFLEXÕES SOBRE A NOVA REGULAMENTAÇÃO ÉTICA DA ADVOCACIA NO BRASIL
}

THE NEW OAB CODE OF ETHICS AND DISCIPLINE - REFLECTIONS ON THE NEW ETHICAL REGULATION OF ADVOCACY IN

BRAZIL

Ítalo Roberto FÜHRMANN ${ }^{1}$

ISSUE DOI: $10.21207 / 1983.4225 .604$

\section{RESUMO}

Lançando mão da análise da espécie delitiva constante no caput do artigo 22 da Lei $n^{\circ} 7.492 / 1986$ (crime de evasão de divisas) e do sistema de compensação de valores, dólar-cabo, o presente trabalho irá analisar a (a)tipicidade existente na atividade dólar-cabo em face ao delito de evasão de divisas.

Palavras Chave: Evasão de divisas. Dólar-cabo. Lei n ${ }^{\circ}$ 74.92/86. Tipicidade.

\section{ABSTRACT}

Taking into account the analysis of the delinquent species in the caput of article 22 of Law No. $7,492 / 1986$ (crime of currency evasion) and the value compensation system, dollar-cap, this paper will analyze the typical nature of dollar-in the face of the crime of evasion of foreign exchange.

Keywords: Currency evasion. Dollar-cable. Law No. 74.92 /86. Typicity.

\footnotetext{
${ }^{1}$ Mestrando em Ciências Criminais pelo Programa de Pós-Graduação em Ciências Criminais (PPGCCRIM) da Pontifícia Universidade Católica do Rio Grande do Sul (PUCRS).
} 
1

\section{CONSIDERAÇÕES INICIAIS DO DELITO DE EVASÃO DE DIVISAS}

O delito de evasão de divisas, disposto no artigo 22 da Lei $\mathrm{n}^{\circ}$ 7.492/86, foi introduzido no Direito Penal brasileiro a fim de possibilitar a punição de condutas que resultassem na saída irregular de divisas do País ou daquelas que deixassem de declarar os depósitos mantidos no exterior. ${ }^{2}$ Para isso, o artigo 22 da Lei $\mathrm{n}^{\circ}$ 7.492/86 dispõe três hipóteses típicas: a primeira de realização de operação de câmbio não autorizada, com o fim de promover evasão de divisas do País (caput), a segunda de evasão de moeda ou de remessa de divisa para o exterior sem autorização legal (parágrafo único, $1^{\mathrm{a}}$ parte), e, a terceira, de manutenção de depósitos no exterior não declarados à autoridade competente (parágrafo único, $2^{\mathrm{a}}$ parte).

\subsection{DA CONDUTA DE EFETUAR A EVASÃO DE DIVISAS (ART. 22, CAPUT, DA LEI № 7.492/86)}

O caput do artigo 22, da Lei $\mathrm{n}^{\circ} 74.92 / 1986$, ao criminalizar a conduta de "efetuar operação de câmbio não autorizada, com o fim de promover evasão de divisas do País" inclui no ordenamento jurídico brasileiro, como objeto material, "o valor resultante da operação de câmbio não autorizada", ${ }^{3}$ razão pela qual sua objetividade jurídica específica reside na proteção sobre "determinadas operações de câmbio destinadas

\footnotetext{
${ }^{2}$ SCHMIDT, Andrei Zenkner; FELDENS, Luciano. O crime de evasão de divisas. Rio de Janeiro: Lumen Juris, 2006, p.158.

${ }^{3}$ SCHMIDT, Andrei Zenkner; FELDENS, Luciano. O crime de evasão de divisas. Rio de Janeiro: Lumen Juris, 2006, p.162. No mesmo sentido: FELIX, Yuri, Evasão de divisas: breves considerações à luz da política cambial brasileira. FRANCO, Alberto Silva; LIRA, Rafael (Coord.). Direito penal econômico: questões atuais. p.359-378. São Paulo: Revista dos Tribunais, 2011, p.370.
} 
à remessa de valores ao exterior" ${ }^{\prime 4}$, primando pelo bom funcionamento do mercado de câmbio e de reservas cambiais. ${ }^{5}$

Tendo em vista que os contratos estão estreitamente relacionados com a dinâmica da economia, já que é o instrumento pelo qual a circulação de bens e serviços se dá dentro do mercado, não é difícil perceber o quão importante seria o alinhamento desse instituto com as políticas de proteção dos recursos naturais, de modo a incluir cláusulas que contemplassem a preocupação ecológica. Em consonância com essa visão, enfatiza Saldanha ${ }^{6}$ :

No contexto em que se preza pelo desenvolvimento sustentável, não somente a norma jurídica ambiental propriamente dita deve servir como instrumento no alcance de objetivos que estejam relacionados a este valor, devendo haver um uso comum de ferramentas jurídicas, novas ou velhas, voltado para o alcance da sustentabilidade. E é nesse contexto no qual não se deve falar apenas em função social das relações contratuais, e sim enfatizar seus fins socioambientais.

Configura-se como uma urgência, pois, o proveito da contribuição que pode ser dada pelos contratos na luta pela superação da crise ecológica em evidência, desde que esses instrumentos sejam reconsiderados no sentido de se realocar hierarquicamente os princípios que os cer-

\footnotetext{
${ }^{4}$ SCHMIDT, Andrei Zenkner; FELDENS, Luciano. O crime de evasão de divisas. Rio de Janeiro: Lumen Juris, 2006, p.162. Ainda, para Nucci a "credibilidade do mercado financeiro e a proteção ao investidor" estão diretamente ligadas à objetividade jurídica, na medida em que "a realização de câmbio ilegal, buscando retirar moeda estrangeirado país, tem capacidade de lesar a saúde financeira das instituições, comprometendo a política econômico-financeira do Estado, prejudicando, pois, em último grau, o próprio investidor" (NUCCI, Guilherme de Souza. Leis penais e processuais penais comentadas. 4.ed. São Paulo: Revista dos Tribunais, 2009, p.1114).

${ }^{5}$ SCHMIDT, Andrei Zenkner; FELDENS, Luciano. O crime de evasão de divisas. Rio de Janeiro: Lumen Juris, 2006, p.162; TORTIMA, José Carlos. Crimes contra o sistema financeiro nacional (uma contribuição ao estudo da Lei ${ }^{\circ}$ 7.492/86). 2.ed. Rio de Janeiro: Lumen Juris, 2002, p.135. BALTAZAR JUNIOR, José Paulo. Crimes federais. 8.ed. Porto Alegre: Livraria do Advogado, 2012, p.471.

${ }^{6}$ SALDANHA, Alexandre Henrique Tavares. Função socioambiental dos contratos e instrumentalidade pró- sustentabilidade: limites ao exercício de autonomias públicas e privadas. Veredas do Direito: Direito Ambiental e Desenvolvimento Sustentável, Belo Horizonte, v. 8, n. 16, p.99-114, 2011. Disponível em: <http://www.domhelder.edu.br/revista/index.php/veredas/article/view/212/187>. Acesso em: 25 set. 2015.
} 
cam, em outras palavras, desde que se ponha como prioridade o atendimento ao princípio socioambiental.

\section{CONSIDERAÇÕES FINAIS}

O presente trabalho buscou trazer as principais conclusões sobre a tutela penal no controle do tráfego de moeda, especificadamente no que se refere à atipicidade penal das operações dólar-cabo. Com esse objetivo, analisaram-se as duas das hipóteses legais constantes no artigo 22 da Lei $\mathrm{n}^{\mathrm{o}}$ 7.492/1986, para, finalmente, discorrer acerca do sistema paralelo de remessa de valores ao exterior, denominado dólar-cabo, e analisar seu enquadramento típico.

\section{REFERÊNCIAS}

ALMEIDA DUARTE, Maria Carolina. Crimes contra o sistema financeiro nacional: uma abordagem interdisciplinar. Rio de Janeiro: Lumen Juris, 2003.

ARAS, Vladimir. Lavagem de dinheiro, evasão de divisas e cooperação internacional. Rocha, João Carlos de Carvalho et al. (Coord.). Crimes contra o sistema financeiro nacional: 20 anos da Lei 7.492/1986. p. 197-240. Belo Horizonte: Del Rey, 2006.

BALTAZAR JUNIOR, José Paulo. Crimes federais. 8.ed. Porto Alegre: Livraria

The new code of ethics and discipline of the Order of Attorneys of Brazil Reflections on the new Law of Attorney Ethics Regulation in Brazil 
Resumo: O presente artigo aborda os principais aspectos do novo código de ética e disciplina da $\mathrm{OAB}$ de 2015. Trata-se de nova regulamentação ética do exercício profissional do advogado, como imperativo decorrente da nova dinâmica das relações sociais e da alteração do contexto social e profissional verificado ao longo dos últimos vinte anos. Não obstante o núcleo estrutural do antigo Código tenha sido preservado em termos de princípios gerais, alguns desdobramentos e regulamentações inovaram sobremaneira a nova sistemática da atuação ético-profissional da advocacia, o que, de fato, deve ser levado ao conhecimento dos advogados para a adequação das suas condutas a novos patamares estabelecidos pela Ordem dos Advogados do Brasil.

Palavras-Chave: Novo Código de Ética; OAB; Advocacia.

Abstract: This article discusses the main aspects of the new code of ethics and discipline of the Order of Attorneys of Brazil, promulgated in 2015. It's about new ethics rules of professional lawyer as an imperative due to the new dynamics of social relations and to the change of the social and professional context checked over the past twenty years. Notwithstanding the structural core of the old code has been preserved in terms of general principles, some developments and regulations greatly innovated the new system of ethical and professional practice of law, which, in fact, should be brought to the attention of the lawyers for the adequacy their behavior to new levels established by the Brazilian Bar Association.

Keywords: New Code of Ethics; Order of Attorneys of Brazil; Lawyers.

"Para julgar um homem, para determinar o seu valor social, o mundo considera, em primeiro lugar, o modo como ele exerce a sua profissão". Rudolf von Jhering, jurista alemão do século XIX.

“J'aurais voulu être avocet; c'est le plus bel état du monde". Voltaire, filósofo francês do século XVIII.

\section{I - Considerações Introdutórias}

É indubitável que os parâmetros éticos de uma determinada sociedade são influenciados, e até mesmo modificados, com o decorrer do tempo, exigindo-se do Direito uma atualização permanente sobre o padrão de conduta ética e moral, mormente face às mais variadas exigências sociais provocadas pelo avanço técnico e científico no contexto da pós- 
modernidade ${ }^{7}$. Ainda que a fonte precípua das normas sociais de conduta ética e moral provenham do costume e de um juízo de valor coletivo do que é o bem e o justo, mister se faz "codificar a ética", especialmente quando necessária a garantia jurídica da sanção a infrações éticodisciplinares, assim como estabelecer um patamar mínimo de segurança jurídica e previsibilidade a seus destinatários ${ }^{89}$. Neste viés, cumpre registrar o pensamento do jurista uruguaio Eduardo Juan Couture, consagrado mundialmente pelo seu decálogo dos deveres do advogado, que fundamenta a razão de renovações periódicas das normas que estabelecem deveres éticos para a advocacia. Segundo Couture:

"A advocacia e as formas de seu exercício são experiências históricas. Suas necessidades e também seus ideais transformam-se com o decorrer do tempo e novas exigências vão surgindo ante o espírito do homem. Por esta razão, é necessário repensar periodicamente os mandamentos para ajustá-los às novas realidades" 10

As prerrogativas profissionais da advocacia, pública ou privada, que visam tutelar a mais ampla possível liberdade profissional do advogado, ainda que se destinem "diretamente" aos causídicos, tem por escopo a proteção e garantia do patrimônio, da liberdade e da honra dos cidadãos, bem como dos fins sociais e institucionais do Estado, constituindo prerrogativas jurídicas para a defesa dos clientes e, em última análise, da própria cidadania. Cumpre registro que a própria Constituição Federal define que o Advogado é indispensável à administração da Justiça, cumprindo o relevantíssimo papel de "elo" que liga o cidadão ao Poder Judi-

\footnotetext{
${ }^{7}$ A pós-modernidade pode ser compreendida enquanto o processo histórico de mudanças paradigmáticas no modo de se pensar a sociedade e suas instituições, designadamente a partir da crise das ideologias no final do século XX. Cf. por todos, LYOTARD, Jean-François. A Condição PósModerna. Rio de Janeiro: José Olympio, 2008.

${ }^{8}$ Cumpre destacar que, dentre as competências funcionais do Tribunal de Ética e Disciplina, está a de responder, em caráter consultivo, a dúvidas e incertezas de advogados em relação à atuação éticoprofissional. (Art. 71, inciso II do CED/2015).

${ }^{9}$ Conforme o art. $9^{\circ}$, caput, c/c art. $10^{\circ}$, caput, do Regulamento Geral do Estatuto da Advocacia e da OAB, os destinatários (obrigados) das normas insculpidas tanto no Estatuto (Lei Federal 8906/94) quanto no Código de Ética profissional, para além dos advogados privados, são os integrantes da Advocacia-Geral da União, da Defensoria Pública, das Procuradorias e Consultorias Jurídicas dos Estados, do Distrito Federal, dos Municípios, das Autarquias e das Fundações Públicas.

${ }^{10}$ Cf., COUTURE, Eduardo. Os Mandamentos do Advogado. Porto Alegre: Fabris, 1979. p. 9-10.
} 
ciário, efetivando, na prática, o devido processo legal, a ampla defesa, o contraditório e o próprio acesso à justiça ${ }^{11}$. Diferentemente de tempos pretéritos, donde tanto as normas deontológicas de condutas éticas e morais quanto a disciplina, seleção e organização interna da OAB estavam previstos no estatuto da advocacia (Lei $n^{\circ} 4215 / 63$ ), a partir do novel diploma regulatório da profissão causídica, a saber a Lei $n^{\circ} 8906 / 94$, os deveres éticos da advocacia constam num rol normativo apartado das normas que definem a capacidade postulatória (jus postulandi) ${ }^{12}$, as prerrogativas profissionais, as infrações disciplinares, a estrutura e natureza jurídica da OAB, a inscrição no respectivo Conselho Seccional, bem como os chamados casos que configuram impedimentos e incompatibilida$\operatorname{des}^{13}$.

Neste viés, recentemente foi elaborado e promulgado o novo Código de Ética profissional dos advogados, com ampla e irrestrita participação da comunidade jurídica brasileira, em especial dos advogados, bem como de importantes segmentos da sociedade civil. O novo estatuto ético-disciplinar da Advocacia entrará em vigor na data do dia 02.05.2016, após o decurso da vacatio legis prevista em seu artigo 79. Houve alterações significativas, designadamente no que concerne à publicidade, frente ao avanço tecnológico das novas mídias, aos honorários advocatícios, assim como a necessária atualização dos parâmetros éticos e morais consentâneos com o advento de novas, e mais dinâmicas, relações sociais e com o imperativo ético-nacional de combate inexorável à corrupção e aos atos imorais na esfera pública e privada ${ }^{14}$. Não temos a pretensão de esgotar o tema proposto, muito menos de figurar como guar-

\footnotetext{
${ }^{11}$ Segundo a Lei 8.906/94, são atividades privativas de advocacia a postulação a órgão do Poder Judiciário e aos juizados especiais, bem como as atividades de consultoria, assessoria e direção jurídicas.

${ }^{12}$ Cf. a distinção traçada entre o chamado jus postulandi - capacidade postulatória - e o direito de petição, positivado no art. $5^{\circ}$, inc. XXXIV, alínea "a" da CF/88, pelo Supremo Tribunal Federal (MI 772-AgR/RJ, Rel Min. Celso de Mello, julgado em 24.10.2007).

${ }^{13}$ De forma diversa se dá nos Estados Unidos, onde o Código de Responsabilidade Profissional, promulgado pela ABA em 1969, aborda os cânones éticos, as considerações éticas e as regras disciplinares, em um único instrumento normativo, que se estende, inclusive, para não profissionais da advocacia que, de alguma forma, se vinculam profissionalmente ao advogado, como seus funcionários no escritório. Cf. MODEL CODE OF PROFESSIONAL RESPONSIBILITY - American Bar Association. Disponível em: http://www.americanbar.org. Data de acesso: 20/04/2016.

${ }^{14}$ Em contexto político e social recente da nação, manifestações populares contra atos de corrupção e imoralidade administrativa tomaram as ruas das principais cidades brasileiras, com destaque para as ocorridas em junho de 2013 e março de 2016, embora com enfoques distintos.
} 
diães absolutos da ética e da moral, num sentido eminentemente retórico e desprovido de aplicabilidade prática. O tema da ética se torna cada vez mais importante no Brasil, e deve ser tratado de forma séria, evitando-se ufanismos e paixões irracionais, que apenas servem para debilitar, banalizar e desacreditar a discussão.

O presente texto tem como escopo principal a análise sistemática, sob um viés jurídico, do novo Código de Ética Profissional dos advogados, destacando as principais alterações no que se refere à conduta e ao exercício ético e moral da advocacia. Neste mister, cumpre consignar que intentamos aclarar eventuais dúvidas e incertezas dos advogados em relação às novas regras de conduta ética, estabelecendo maios segurança jurídica e previsibilidade ao exercício profissional, não dispensando as devidas referências ao Estatuto da Advocacia e da Ordem dos Advogados do Brasil (Lei no 8.906/94), ao Regulamento Geral do Estatuto e aos Provimentos e Resoluções do Conselho Federal da OAB que se fizerem pertinentes. Em termos estruturais, o texto abordará inicialmente o conceito de ética, relacionando-o ao aspecto específico da ética profissional da advocacia; as origens históricas dos atos normativos regulatórios da conduta profissional do advogado no Direito brasileiro, os principais tópicos sobre as normas de conduta ético-jurídica, destacando as principais mudanças trazidas com o advento do Código de Ética e Disciplina da OAB de 2015.

\section{I - Ética: Em busca de uma Delimitação Conceitual}

Ética e moral são expressões cuja origem remonta ao limiar da civilização ocidental. Ethos, em grego, significa costume, hábito, isto é, normas adquiridas pelo uso reiterado de uma prática social. Mos, em latim, tem significado similar, reportando-se aos costumes sociais verificados na antiga Roma ${ }^{15}$. Etimologicamente, podemos inferir que os dois termos possuem uma ligação umbilical com às práticas sociais de uma determinada sociedade, porém, desde uma perspectiva contemporânea, a Ética se situa num campo eminentemente teórico-científico, cuja finalidade é a formulação de normas deontológicas para o agir moral, buscando sua fundamentação última e legitimação. Conforme o entendimento de José Renato Nalini, "a ética é a ciência dos costumes, por ter um objeto,

${ }^{15}$ Cf. NALINI, José Renato. Ética Geral e Profissional. 12a ed. São Paulo: Editora Revista dos Tribunais, 2015. p. 40. 
leis e métodos próprios. Já a moral não é ciência, senão objeto da ciência"16.

Podemos delimitar, enquanto definição conceitual, que a ética se constitui em uma parte da filosofia que se destina à reflexão sobre as condutas e o agir moral dos indivíduos. Neste sentido, ética é uma disciplina teórica sobre uma prática humana, que é o comportamento moral ${ }^{17}$. No âmbito da ética, é que podemos definir as prescrições para o desenvolvimento e aprimoramento do agir humano e social, desde uma perspectiva crítica e reflexiva. Para Tereza Rodrigues Vieira e João Nery dos Passos Martins, a ética profissional, como disciplina, pode ser conceituada como:

"Ética profissional é o conjunto de princípios e regras que regem a conduta de determinada profissão, considerando suas particularidades. Trata-se de um padrão de comportamento que se torna (moral e legalmente) imprescindível a quem deseja desempenhar tal ofício, seja em relação aos demais colegas, aos clientes, à sociedade e, inclusive, a si próprio." 18

Sem embargo, o conceito de ética também se relaciona de forma umbilical com o tema dos direitos fundamentais, de índole constitucional ${ }^{19}$. Conforme as palavras do jurista alemão Konrad Hesse "um importante sinal do desenvolvimento mundial contemporâneo é a crescente importância atribuída aos direitos fundamentais" ${ }^{20}$. Ética e direitos fundamentais são conceitos indissociáveis, e devem ser compreendidos em sua mútua interação e interdependência.

As normas de regulamentação ético-profissional são providas de força normativa, e devem ser respeitadas sob pena de violação legal. Segundo Paulo Luiz Netto Lôbo, relator do Regulamento Geral do Estatuto

\footnotetext{
${ }^{16}$ Ibidem. p. 41.

${ }^{17}$ VIEIRA, Tereza Rodrigues; MARTINS, João Paulo Nery dos Passos. Ética no Direito. Petrópolis, RJ: Vozes, 2007. p. 15.

${ }^{18}$ Ibidem. p. 18.

${ }^{19}$ Para uma compreensão abrangente sobre o status constitucional da advocacia, remetemos o leitor para a obra de Gladston Mamede, intitulada A Advocacia e a Ordem dos Advogados do Brasil. $2^{\mathrm{a}}$ ed. São Paulo: Atlas, 2003. p. 65.

${ }^{20}$ HESSE, Konrad. Bedeutung der Grundrechte, in: BENDA, Ernst; MAIHOFER, Werner; VOGEL, Hans-Jochen (Orgs.). Handbuch des Verfassungsrechts der Bundesrepublik Deutschland. 2a ed. Berlin-New York: de Gruyter, 1994. p. 127.
} 
da Advocacia e da OAB, a ética profissional impõe-se ao advogado em todas as circunstâncias e vicissitudes de sua vida profissional e, inclusive, pessoal que possam repercutir no conceito público e na dignidade da advocacia. Ademais, ensina o autor que os deveres éticos consignados no Código de Ética e Disciplina não são meras recomendações de bom comportamento, mas normas jurídicas de obrigatoriedade compulsória, que devem ser cumpridas com rigor, sob pena de cometimento de infração disciplinar punível com a sanção de censura (art. 36 do EOAB), se outra mais grave não for aplicável ${ }^{21}$.

Com efeito, para o constitucionalista espanhol Fernando Garrido Falla, quando utilizamos a palavra dignidade podemos toma-la em dois sentidos distintos; o primeiro como forma de alguém se comportar, de se portar frente a terceiros, que pode ser de forma digna ou indigna. $\mathrm{O}$ segundo se refere à importância que se concede a um ser, independentemente da forma como se comporte ${ }^{22}$. Para fins do novo Código de ética, estamos lidando com a primeira acepção, de modo que a dignidade do advogado está estritamente vinculada com o modo de sua conduta no exercício profissional.

\section{II - Antecedentes históricos e a OAB: O percurso normativo para a Criação do Código de Ética e Disciplina da OAB.}

No limiar da civilização, as expressões advocatus ${ }^{23}$, patronus e causidicus já representavam um alto senso de importância e dignidade da profissão que tinha como escopo a defesa de pessoas, direitos, bens e interesses. No Brasil, como se sabe, a origem da advocacia remonta à formação dos cursos jurídicos nacionais, especificamente ao ano de 1827, por intermédio do então ministro da Justiça José Feliciano Fernandes Pinheiro (Visconde de São Leopoldo) ${ }^{24}$.

\footnotetext{
${ }^{21}$ LÔBO, Paulo Luiz Netto. Comentários ao Estatuto da Advocacia e da OAB. $3^{\mathrm{a}}$ ed. São Paulo: Saraiva, 2002. p. 165.

${ }^{22}$ Cf. FALLA, Fernando Garrido. Comentarios a la Constitución. $3^{\mathrm{a}}$ ed. Madrid: Civitas, 2001. p. 197.

${ }^{23}$ A partir do século II depois de Cristo, este foi o termo que prevaleceu para a caracterização do profissional que tinha a incumbência da defesa jurídica dos indivíduos. Cf. LOBÔ, op. cit.,. p. 18.

${ }^{24}$ As primeiras Escolas Superiores de Direito foram criadas em 11.08.1827, nas cidades de Olinda e São Paulo. Até hoje, a data marca, em todo o Brasil, o dia do Advogado.
} 
No cenário jurídico-institucional gaúcho ${ }^{25}$, merece destaque a atuação marcante de Leonardo Macedônia, primeiro presidente do Instituto dos Advogados do Rio Grande do Sul (IARGS) ${ }^{26}$, bem como da Ordem dos Advogados do Brasil, seccional gaúcha, em 1932 ${ }^{27}$. Mediante a participação efetiva do IARGS, dentre outros Institutos Estaduais, foi expedido pelo então Chefe do Governo provisório, Getulio Vargas, o decreto $\mathrm{n}^{\mathbf{o}}$ 19.408, de 19 de outubro de 1930, cujo art. 17 estampava a seguinte redação:

"Fica criada a Ordem dos Advogados Brasileiros, órgão de disciplina e seleção dos advogados, que se regerá pelos estatutos que forem votados pelo Instituto dos Advogados Brasileiros, com a colaboração dos Institutos dos Estados, e aprovados pelo Governo" 28 .

Até o ano de 1963, data em que entrou em vigor a Lei 4.215, configurando o primeiro Estatuto da Advocacia e da OAB, o exercício

\footnotetext{
${ }^{25}$ Em termos nacionais, o Instituto dos Advogados brasileiros foi criado em 07 de setembro de 1843, e teve como membros os insignes juristas Augusto Teixeira de Freitas, José Antônio Pimenta Bueno, Nabuco de Araújo, Saldanha Marinho e Ruy Barbosa. Seu primeiro presidente foi Francisco de Montezuma.

${ }^{26}$ O IARGS foi criado em 26 de outubro de 1926, por 169 juristas, entre eles: Arnaldo Ferreira, Adroaldo Mesquita da Costa, Camilo Martins da Costa, Maurício Cardoso, Rui Cirne Lima, Leonardo Macedônia, Osvaldo Vergara, Miguel Tostes e Leonardo Truda. Cf. CABRAL, Sulamita Santos; VIVIANE, Karla; RECH, Nathalia. (Org.). OAB/RS: A História. Porto Alegre: Imprensa Livre, 2012. p. 18. A título ilustrativo, a primeira mulher a se inscrever da seccional do Estado do Rio Grande do Sul se chamava Maria Else Iris Potthoff, aos 22 de março de 1937, obtendo o registro profissional de número 653.

${ }^{27}$ As duas maiores distinções oferecidas até hoje pela Ordem gaúcha homenageiam dois advogados que contribuíram sobremaneira para a institucionalização da OAB-RS, e pela concretização efetiva das prerrogativas dos advogados gaúchos, que são Leonardo Macedônia e Oswaldo Vergara. Trata-se da Comenda Oswaldo Vergara, que homenageia os advogados que se destacam pela atividade profissional e pela ética na advocacia, e a Medalha Leonardo Macedônia, entregue aos ex-presidentes da seccional e das subseções para ratificar os elevados serviços prestados à advocacia gaúcha.

${ }^{28}$ A título ilustrativo, o primeiro presidente da Ordem dos Advogados do Brasil foi Levy Carneiro, em 1932. A criação da Caixa de Assistência dos Advogados se deu por intermédio do Decreto-Lei $\mathrm{n}^{\circ}$ 4563/42, principalmente pelo efetivo papel desempenhado por Oswaldo Vergara. A Caixa de Assistência dos Advogados desempenhou importante papel para a melhora da qualidade de vida de seus membros, oferecendo serviços como auxílio escola, funeral, natalidade, cirúrgico-hospitalar, livraria, ótica, farmácia, centro médico, odontológico e psicoterapêutico. Cf. CABRAL, Sulamita Santos; VIVIANE, Karla; RECH, Nathalia. (Org.). OAB/RS: A História. Porto Alegre: Imprensa Livre, 2012. p. 31.
} 
profissional dos advogados foi regulado pelo decreto 20.784, de 14 de dezembro de $1931^{29}$. O primeiro Código de Ética dos advogados foi promulgado em 25 de julho de 1934, consubstanciando a prioridade imediata da recém-criada $\mathrm{OAB}$ em regulamentar a disciplina ética dos seus membros $^{30}$. Nada obstante, o texto foi elaborado com base no Código de Ética do Instituto dos Advogados de São Paulo (IASP), implementado em 1915. Pode-se dizer que o estatuto ético do IASP foi o primeiro Código de Ética das profissões liberais da América do Sul.

Em termos constitucionais, a primeira Constituição a referir expressamente o nome da Instituição OAB foi a de 18 de setembro de 1946, declarando a obrigatoriedade da participação da Ordem dos Advogados do Brasil em todos os concursos para a magistratura dos Estados federados ${ }^{31}$. Desde então, a OAB temse caracterizado como instância constitucional indispensável à defesa e ao desenvolvimento do Estado de Direito no Brasil, compreendendo-se este, nas palavras de Dieter Grimm, como o Estado que exerce seu domínio político tão-somente com base e no âmbito do Direito ${ }^{32}$. É de se referir que a OAB teve participação efetiva e destacada em momentos históricos cruciais na formação do espírito democrático no Brasil. Já em 1958, dá-se a primeira Conferência nacional dos Advogados, pugnando pela Reforma do Poder Judiciário, pela defesa das prerrogativas da Advocacia e pela qualidade dos cursos jurídicos. Em 1961, a OAB adere à campanha da Legalidade, ao lado da resistência deflagrada no Rio Grande do Sul contra o Golpe que estava sendo desferido ao então presidente constitucionalmente legítimo João Goulart. Ademais, não podemos esquecer do posicionamento da OAB contra a Lei de Segurança Nacional, imposta pelo Regime militar, de 03 de março de 1967, e contra o AI-14, que legalizava a pena de mor-

\footnotetext{
${ }^{29}$ Tal diploma legal entrou em vigor a 15 de novembro do mesmo ano. Apesar de muito bem elaborado, e com alguns dispositivos reproduzidos nos estatutos sucessores, decidiu-se por bem realizar sua atualização por meio da Lei 4.215, de 27 de abril de 1963.

${ }^{30}$ CABRAL, Sulamita Santos; VIVIANE, Karla; RECH, Nathalia. (Org.). OAB/RS: A História. Porto Alegre: Imprensa Livre, 2012 . p. 25.

${ }^{31}$ Ibidem. p. 33.

${ }^{32}$ GRIMM, Dieter. Die Zukunft der Verfassung. Frankfurt am Main: Suhrkamp Taschenbuch Wissenschaft, 1991.p. 159.
} 
te no Brasil. Outros acontecimentos históricos marcaram da mesma forma a participação atuante da $\mathrm{OAB}$ nos rumos políticos nacionais, como a campanha pela Anistia ampla, geral e irrestrita, bem como nas Diretas Já e no processo de Impeachment que cassou o mandato do ex-presidente Fernando Collor ${ }^{33}$.

Desde o ano de 1934, com o advento do primeiro estatuto ético da advocacia brasileira, a Instituição da $\mathrm{OAB}$ sempre demostrou preocupação com o decoro, urbanidade e polidez de seus membros, inclusive no que se refere ao comportamento pessoal dos advogados em suas relações sociais e privadas ${ }^{34}$. Neste sentido, podemos atestar que a disciplina normativa das condutas dos advogados sempre esteve no centro das preocupações e deliberações da Ordem dos Advogados do Brasil, iniciando com o Código de Ética de 1934, perpassando pelo Estatuto da Advocacia de 1963, e culminado com os dois últimos atos normativos, de 1995 e o de 2015, os quais serão objeto de análise nos tópicos que seguem.

\section{III - O Código de Ética e Disciplina da OAB de 13 de Fevereiro de 1995}

Fruto de intensas deliberações, debates e participação da classe dos advogados e dos principais seguimentos da sociedade civil, o Código de Ética e Disciplina de 1995 foi um marco, à época, no que se refere à disciplina ética das condutas dos advogados, tornando-se paradigma para a regulamentação de outras profissões liberais. Tendo como relator o consagrado jurista e professor Modesto Souza Barros Carvalhosa, e sob a chancela do então presidente do Conselho Federal José Roberto Batochio, o Código de Ética dos advogados foi promulgado

\footnotetext{
${ }^{33}$ CABRAL; VIVIANE; RECH (Orgs), op. cit., p. 37 e ss.

${ }^{34}$ Veja-se, por exemplo, o art. $2^{\circ}$, inciso III do novo Código de Ética e Disciplina da OAB, segundo o qual o advogado deve velar por sua reputação pessoal e profissional, assim como o inciso IV, que prescreve aos advogados o empenho permanente do seu aperfeiçoamento pessoal e profissional.
} 
aos 13.02.1995 $5^{35}$, disciplinando âmbitos da conduta profissional dantes não regulamentados sob a perspectiva ética. Participaram da Comissão revisora os insignes juristas Lecínio Leal Barbosa, Robison Baroni, Nilzardo Carneiro Leão, José Cid Campelo e Sergio Ferraz.

De início, cabe a menção ao significativo elenco de deveres éticos arrolados após o dispositivo que consagrou a vinculação estrita da conduta do advogado aos preceitos da moral individual, social e profissional para além dos próprios atos normativos. Já no caput do seu art. $2^{\circ}$, o Código estabelecia que o Advogado é indispensável a administração da justiça, reforçando, no mais, o que dispõe o art. 133 de nossa Carta Magna. Ademais, qualifica o exercício profissional da advocacia, inclusive no seu ministério privado, como de elevada função pública. Em aspecto geral, podemos consignar que o capítulo primeiro do Código de Ética consagrou os seguintes princípios norteadores da advocacia: a) Essencialidade e indispensabilidade ${ }^{36}$; b) Independência; c) Função Social; d) Confiabilidade; e) Não-mercantilização; f) Pessoalidade; e g) Liberdade.

Em relação ao mandato judicial, no art. 13 ficou assente que o advogado, quando da renúncia ao patrocínio, deverá sempre omitir o motivo, ficando responsável pelo processo no prazo estipulado em Lei, sem prejuízo de responder pelos danos causados dolosa ou culposamente aos clientes ou a terceiros. Por seu turno, estipulava o art. 14 que a revogação do mandato judicial por vontade do cliente não o desobriga do pagamento das verbas honorárias contratadas, bem como não retira o direito do advogado de receber o quanto lhe seja devido em

\footnotetext{
${ }^{35} \mathrm{O}$ presente ato normativo entrou em vigor aos 01.03.1995, mediante sua publicação no Diário de Justiça (pp. 4000/4004).

${ }^{36} \mathrm{O}$ princípio da indispensabilidade do advogado para a Administração da Justiça foi relativizado a partir de hipóteses excepcionais previstas no Estatuto da Ordem dos Advogados e nas Leis 9.099/95 e 10.259/01. São elas: a) Impetração de Habeas Corpus em qualquer instância ou Tribunal; b) Processos de competência da Justiça do Trabalho; c) Casos submetidos à Justiça de Paz; d) Causas cujo valor não ultrapasse 20 salários mínimos nos Juizados Especiais Cíveis; e) Visto em ato ou contrato constitutivo de pessoa jurídica passíveis de registro, desde que se trate de microempresa ou empresa de pequeno porte (Lei Complementar 123/06).
} 
eventual verba honorária de sucumbência, calculada proporcionalmente, em face do serviço efetivamente prestado.

$\mathrm{O}$ art. 21 do Código de Ética é de extrema importância e lida com valores éticos e sociais em casos limites ${ }^{37}$. Trata-se dos casos onde atuam advogados na defesa de criminosos que tenham cometido crimes de grande repulsa social. São aqueles criminosos que, em regra, costumam ensejar execração pública, principalmente por meio da imprensa. De fato, a garantia do devido processo legal, da ampla defesa e do contraditório, enquanto verdadeiros direitos fundamentais de caráter judicial previstos em nossa Constituição, devem ser defendidos e concretizados, independentemente da figura do réu no processo, e por isso, ou seja, pela defesa da Constituição no caso concreto, a atuação do advogado nestes casos se torna tão importante e digna de respeito.

O sigilo profissional também foi objeto de regulamentação pelo vetusto Código de Ética. Com efeito, declarou-se o sigilo como prerrogativa inerente à profissão de advogado, somente podendo ser violado em excepcionalíssimas hipóteses, como no caso de ameaça ao direito à vida, honra, ou na hipótese eventual do advogado se ver afrontado pelo próprio cliente, e necessitar expor as informação na sua defesa. $\mathrm{O}$ art. 26 reforçava ainda mais tal prerrogativa, enfatizando que o advogado deve guardar sigilo, mesmo em depoimento judicial, sobre as informações obtidas em razão de seu ofício, cabendo-lhe recusar-se a depor como testemunha em processo no qual funcionou ou deva funcionar, ou sobre fato relacionado com pessoa de quem seja de quem seja ou tenha sido advogado, mesmo que autorizado ou mesmo solicitado pelo constituinte.

No que se reporta à publicidade no meio jurídico, o Código estabeleceu regras de observância rigorosa, com o fito de proporcionar uma igualdade mais efetiva entre advogados em termos de concorrência, ao mesmo tempo de atribuir uma imagem moderada e discreta do exercício

\footnotetext{
${ }^{37}$ Ipsis litteris: Art. 21: É direito e dever do advogado assumir a defesa criminal, sem considerar sua própria opinião sobre a culpa do acusado.
} 
da advocacia no mercado de consumo. Conforme o caput do art. 28, o anúncio dos serviços advocatícios deve ser feito com moderação e discrição, tendo finalidade exclusivamente informativa, vedada sua divulgação em conjunto com outra atividade. Outro tema de importância significativa para o exercício profissional é o dos honorários advocatícios. O antigo código traçava regras claras sobre a garantia contratual, as espécies de honorários advocatícios e os critérios que devem ser levados em consideração para sua adequada fixação ${ }^{38}$.

Por fim, importante consignar que o antigo Código de Ética e Disciplina da $\mathrm{OAB}$ disciplinou pormenorizadamente a competência funcional do Tribunal de Ética e Disciplina (TED) ${ }^{39}$. Tal órgão sancionador tornou-se competente para orientar e aconselhar sobre ética profissional, respondendo às consultas em tese, e, principalmente, julgar os processos disciplinares instaurados pela ocorrência de infrações disciplinares previstas no Estatuto da Advocacia e a Ordem dos Advogados do Brasil ${ }^{40}$.

\footnotetext{
${ }^{38}$ Dispunha o art. 36, ipsis litteris: "Os honorários profissionais devem ser fixados com moderação, atendidos os elementos seguintes: I - a relevância, o vulto, a complexidade e a dificuldade das questões versadas; II - o trabalho e o tempo necessários; III - a possibilidade de ficar o advogado impedido de intervir em outros casos, ou de se desavir com outros clientes ou terceiros; IV - o valor da causa, a condição econômica do cliente e o proveito para ele resultante do serviço profissional; $\mathrm{V}-\mathrm{o}$ caráter da intervenção, conforme se trate de serviço a cliente avulso, habitual ou permanente; VI - o lugar da prestação dos serviços, fora ou não do domicílio do advogado; VII - a competência e o renome do profissional; VIII - a praxe do foro sobre trabalhos análogos."

${ }^{39}$ Como competência complementar, assim previa o art. 50 do CED/95: "Compete também ao Tribunal de Ética e Disciplina: I - instaurar, de ofício, processo competente sobre ato ou matéria que considere passível de configurar, em tese, infração a princípio ou norma de ética profissional; II organizar, promover e desenvolver cursos, palestras, seminários e discussões a respeito de ética profissional, inclusive junto aos Cursos Jurídicos, visando à formação da consciência dos futuros profissionais para os problemas fundamentais da ética; III - expedir provisões ou resoluções sobre o modo de proceder em casos previstos nos regulamentos e costumes do foro; IV - mediar e conciliar nas questões que envolvam: a) dúvidas e pendências entre advogados; b) partilha de honorários contratados em conjunto ou mediante substabelecimento, ou decorrente de sucumbência; c) controvérsias surgidas quando da dissolução de sociedade de advogados."

${ }^{40}$ Conforme dispõe o art. 35 do Estatuto da Advocacia e da OAB, as sanções disciplinares consistem em:

I - censura; II - suspensão; III - exclusão; IV - multa. Ademais, complementa seu parágrafo único dispondo que as sanções devem constar dos assentamentos do inscrito, tão-somente após o trânsito em julgado da decisão, não podendo ser objeto de publicidade a de censura.
} 


\section{IV - O NOVO CÓDIGO DE ÉTICA E DISCIPLINA DA OAB DE 04 DE NOVEMBRO DE 2015}

O mais recente ato normativo de regulamentação ética das condutas pessoais e profissionais do advogado exsurgiu recentemente, mais precisamente em fins do ano de 2015. Trata-se de novel diploma normativo vocacionado a dar maior abrangência e completude ao Código revogado, especialmente no que se refere ao desenvolvimento tecnológico das novas mídias sociais, ao avanço técnico-científico e ao aumento significativo do número de advogados e cursos jurídicos no País ${ }^{41}$.

Sob a relatoria originária do jurista Paulo Roberto de Gouvêa Medina, com relatoria final em plenário de Humberto Henrique Fernandes do Rêgo, e sob a chancela do então presidente do Conselho Federal da OAB, Marcus Vinicius Furtado Coêlho, o novo Código de Ética dos advogados foi promulgado aos 04 de novembro de 2015, com previsão para sua entrada em vigor, após a vacatio legis do seu art. 79, em 02 de maio de 2016. Trata-se, sem dúvida, de texto adaptado à realidade contemporânea e condizente com o novo contexto social no qual avulta, sistematicamente, a atuação profissional dos advogados para o efetivo exercício da cidadania ${ }^{42}$.

Em termos substanciais, os alicerces que sustentavam o antigo Código de Ética e Disciplina se mantiveram no novo ato normativo, designadamente no que se refere aos deveres éticos do advogado, consubstanciados, em regra, no $\S$ único, do art. $7^{\circ}$. Neste contexto, citam-se, como mais significativos, o dever de preservar, em sua conduta, a honra, a nobreza e a dignidade da profissão, zelando pelo caráter de essencialidade e indispensabilidade da advocacia; o dever de atuar com destemor, independência, honestidade, decoro, veracidade, lealdade, dignidade e boa-fé; o dever de velar por sua reputação pessoal e profissional; o dever de estimular, a qualquer tempo, a conciliação e a mediação entre os litigantes, prevenindo, sempre que possível, a instauração de litígios; o dever de abster-se de entender-se diretamente com a parte adversa que tenha pa-

\footnotetext{
${ }^{41}$ No Brasil, hoje, estão registrados nos Conselhos Seccionais quase um milhão de advogados. Em relação aos cursos jurídicos, estes já ultrapassaram o número de 1.200 em todo o País, correspondendo a uma quantidade superior ao número de cursos de Direito somados no resto do mundo.

${ }^{42}$ Segundo os dados do levantamento anual Justiça em Números, feito pelo Conselho Nacional de Justiça (CNJ), em 2014 passaram pela jurisdição dos 90 tribunais brasileiros, 99,7 milhões de processos.
} 
trono constituído, sem o assentimento deste, assim como de contratar honorários advocatícios em valores aviltantes, dentre outros.

De forma inédita, o capítulo II do Código versa sobre as atividades da advocacia pública, deixando claro que tal atividade também se submete aos ditames das normativas éticas e estatutárias ${ }^{43}$. No que dialoga com a atuação do profissional da advocacia em processo-crime, o art. 23, reforçando o que já havia expresso no Código anterior, estabelece que é direito e dever do advogado assumir a defesa criminal, sem considerar sua própria opinião sobre a culpa do acusado. Complementa no sentido de que não há causa criminal indigna de defesa, cumprindo ao advogado agir, como defensor, no sentido de que a todos seja concedido tratamento condizente com a dignidade da pessoa humana, sob a égide das garantias constitucionais.

O Novo Código de Ética e Disciplina da OAB inova mais uma vez ao estabelecer expressamente as condições jurídicas e éticas para a atuação na Advocacia pro bono ${ }^{44}$. Trata-se de instrumento jurídico idôneo para a prestação de serviços advocatícios aos mais necessitados economicamente, como corolário da elevada função social e de interesse público exercida pelo advogado ${ }^{45}$, ainda que sob certos condicionamentos e limitações. A advocacia pro bono pode ser exercida em favor de pessoas naturais que não dispuserem de recursos para, sem prejuízo do próprio sustento, - e neste ponto não há extensão ao sustento da família do advogado -, contratar advogado. Do mesmo modo, a advocacia pro bono não pode ser utilizada para fins político-partidários ou eleitorais, nem beneficiar instituições que visem a tais objetivos, ou como instrumento de publicidade para captação de clientela.

Relativamente ao mandato judicial, a nova normativa ética dos advogados dispõe que a renúncia do advogado à causa deve ser feita, necessariamente, sem a menção do motivo que a determinou, fazendo

\footnotetext{
${ }^{43}$ Art. $8^{\circ}$, caput, do Código de Ética de 2015: "As disposições deste Código obrigam igualmente os órgãos de advocacia pública, e advogados públicos, incluindo aqueles que ocupem posição de chefia e direção jurídica."

${ }^{44}$ Conforme preceitua o art. $30, \S 1^{\circ}$ do $\mathrm{CED} / 15$ : “Considera-se advocacia pro bono a prestação gratuita, eventual e voluntária de serviços jurídicos em favor de instituições sociais sem fins econômicos e aos seus assistidos, sempre que os beneficiários não dispuserem de recursos para a contratação de profissional."

${ }^{45}$ Basta a referência ao art. $2^{\circ}$, caput do CED/15 c/c art. $2^{\circ}$, caput e $\S 1^{\circ}$ do Estatuto da OAB (Lei ${ }^{\circ}$ 8906/94).
} 
cessar a responsabilidade profissional pelo acompanhamento do feito, desde que decorrido o prazo estabelecido no Estatuto da Advocacia ${ }^{46}$. De outra banda, por disposição expressa do art. 17 do CED/15, a revogação do mandato por parte do cliente não o desobriga de arcar com a devida verba honorária contratada, inclusive no que se refere aos honorários advocatícios de sucumbência, calculada proporcionalmente em face do serviço efetivamente prestado. Mantêm-se a sistemática quanto ao substabelecimento do mandato, o qual deverá ser previamente comunicado ao cliente quando for sem reservas de poderes. Tratando-se de substabelecimento com reservas de poderes, que se configura como ato pessoal do advogado da causa, os honorários deverão ser antecipadamente ajustados entre o substabelecente e o substabelecido.

Importante imperativo ético da conduta profissional dos advogados está previsto no art. 28 do novo Código, que identifica como características fundamentais do exercício profissional o emprego de linguagem escorreita e polida, assim como a observância da boa técnica jurídica. Neste sentido, a OAB se preocupou tanto com o aspecto gramatical e ortográfico da produção textual dos advogados em juízo, não descurando do domínio técnico-processual quando da atividade forense. Tal dispositivo atenta-se para o binômio técnica-linguagem, considerando-se que a palavra e o texto são, de fato, a matéria prima com a qual a advocacia é exercida $^{47}$.

No que pertine à garantia e dever do sigilo profissional, o código de ética e disciplina foi bastante arrojado e abrangente, determinando apenas casos excepcionalíssimos que dariam ensejo à restrição de tal direito $^{48}$, que, no mais, constitui o principal bastião do princípio da confiabilidade entre patrono e cliente. Com efeito, dispõe o Código que o advogado tem o dever de guardar sigilo dos fatos de que tome conhecimento no exercício da profissão, inclusive das informações que tenha obtido por conta do exercício de função desempenhada na Ordem dos Advogados do Brasil. O sigilo profissional é de ordem pública, independente de

\footnotetext{
${ }^{46}$ Art. $5^{\circ} \mathrm{O}$ advogado postula, em juízo ou fora dele, fazendo prova do mandato. $\S 3^{\circ} \mathrm{O}$ advogado que renunciar ao mandato continuará, durante os dez dias seguintes à notificação da renúncia, a representar o mandante, salvo se for substituído antes do término desse prazo.

${ }^{47}$ Art. 34, inciso XXIV do Estatuto da OAB/94 - Constitui infração disciplinar punível com suspensão incidir em erros reiterados que evidenciem inépcia profissional.

${ }^{48}$ Art. 37 do Novo Código de Ética da OAB: "O sigilo profissional cederá em face de circunstâncias excepcionais que configurem justa causa, como nos casos de grave ameaça ao direito à vida e à honra ou que envolvam defesa própria".
} 
solicitação realizada pelo cliente, presumindo-se confidenciais todas as comunicações efetuadas entre advogado e cliente. Tais regras estendemse às funções exercidas pelo advogado na condição de conciliador, mediador e árbitro. Por fim, consigna o novo texto normativo que o advogado não é obrigado a depor, em processo ou procedimento judicial, administrativo ou arbitral, sobre fatos a cujo respeito deva guardar sigilo profissional (Art. 38 do NCED).

A publicidade para o oferecimento de serviços advocatícios continua sob forte regramento disciplinar, de modo a qualificar a advocacia como atividade não-mercantil, fora do contexto do serviços estritamente comerciais. Para tanto, o caput do art. 39 expressa, ipsis litteris "a publicidade profissional do advogado tem caráter meramente informativo e deve primar pela discrição e sobriedade, não podendo configurar captação de clientela ou mercantilização da profissão". Tal limitação, embora restrinja as formas de oferecimento no mercado dos serviços advocatícios, traz, sem dúvida, uma vantagem aos advogados, que se configura na sua não incidência enquanto típico fornecedor no mercado de consumo, não se sujeitando à chamada responsabilidade objetiva para fins de ressarcimento por danos causados ao consumidor (Art. 14 do Código de Defesa do Consumidor).

Neste viés, dentre as principais vedações ao exercício da publicidade por parte dos advogados, encontram-se: a) a veiculação de publicidade por meio de rádio, cinema e televisão; b) o uso de outdoors, painéis luminosos ou formas assemelhadas de publicidade; c) inscrições em muros, paredes, veículos, elevadores ou em qualquer espaço público; d) a divulgação de serviços de advocacia juntamente com a de outras atividades ou a indicação de vínculos entre uns e outras; e) o fornecimento de dados de contato, como endereço e telefone, em colunas ou artigos literários, culturais, acadêmicos ou jurídicos, publicados na imprensa, bem assim quando de eventual participação em programas de rádio e televisão, ou de veiculação de matérias pela internet, sendo permitida a referência a e-mail; f) a utilização de mala-direta, a distribuição de panfletos ou formas assemelhadas de publicidade, com intuito de captação de clientela. De forma inédita, o novo Código previu, expressamente, a licitude da publicidade por meio da internet (Facebook, blogs, sites etc.), inclusive para o envio de mensagens a destinatários certos, desde que não impliquem em oferecimento de serviços, nem em captação de clientela, bem como respeitem as diretrizes disciplinares aplicáveis para as outras formas de publicidade. 
Por derradeiro, insta uma menção à novidade inserida na sistemática dos honorários advocatícios, facilitando, na prática, o recebimento da verba honorária por parte dos advogados. Trata-se, com efeito, da possibilidade do advogado em levar a protesto o cheque ou a nota promissória emitida pelo cliente em favor do seu patrono, depois de frustrada a tentativa de recebimento amigável (art. 52, § único do CED/15). Ademais, torna-se expressamente lícito ao advogado ou à sociedade de advogados empregar, para o recebimento de honorários, sistema de cartão de crédito, mediante credenciamento junto a empresa operadora do ramo (art. 53, caput do CED/15).

Sem embargo, e parafraseando o jurista norte-americano Michel Rosenfeld, o contexto, inclusive cultural, no qual se insere a norma jurídica, desempenha um papel extremamente significativo para a construção de sua própria identidade, para além do seu conteúdo normativo ${ }^{49}$, de modo que para uma definição mais precisa e abrangente do novo Código de Ética e disciplina da OAB, há que se aguardar o modo como será recepcionada pela comunidade jurídica e a forma como se dará a sua aplicação prática no cotidiano forense.

\section{CONCLUSÃO}

Em termos conclusivos, se faz de bom alvitre reverberarmos os dizeres de Paulo Luiz Netto Lôbo, que aduz o fato de que a ética profissional deve se impor, de forma inequívoca, ao advogado em todas as circunstâncias e vicissitudes de sua vida profissional e pessoal que possam repercutir no conceito público e na dignidade da advocacia, de modo que os deveres éticos consignados no Código não são meras recomendações de bom comportamento, mas normas jurídicas dotadas de obrigatorieda$d e$, e que devem ser cumpridas à risca, sob pena de cometimento de infração disciplinar punível com a sanção de censura, conforme predispõe o art. 36 do Estatuto da Advocacia e da OAB - Lei no 8906/94, se outra mais grave não for aplicável ${ }^{50}$. De fato, trata-se de regras deontológicas dever de fazer - providas de força jurídico-normativa, submetendo todos

\footnotetext{
${ }^{49}$ Cf. ROSENFELD, Michel. Constitutional Identity, in: ROSENFELD, Michel; SAJÓ, András (Orgs.). The Oxford Handbook of Comparative Constitutional Law. Oxford: Oxford University Press, 2012. p. 757.

${ }^{50}$ LÔBO, op. cit., p. 165.
} 
advogados a sua estrita observância sob pena de infração disciplinar, processada e julgada pelo respectivo Tribunal de Ética e Disciplina (TED) $)^{51}$. Como afirma Haroldo Cardella, o Estatuto e o Código de Ética estabelecem normas deontológicas referentes à conduta pessoal do advogado e ao seu dever para com a classe, devendo este proceder de forma a tornar-se merecedor de respeito e contribuir para com o prestígio da classe e da $\operatorname{advocacia}^{52}$.

Por vezes, notamos que o exercício da advocacia gera uma certa impopularidade, designadamente pela falta de informações claras e objetivas quanto à elevada função social que desempenha o advogado. Como bem afirma o advogado francês Henri Robert, o cliente, de fato, só recorre ao advogado na adversidade, quando se vê em meio a problemas, aborrecimentos, graves preocupações, responsabilidades que às vezes lhe comprometem seriamente a honra, a liberdade e o patrimônio ${ }^{53}$. Com efeito, os advogados são as testemunhas profissionais dos maus dias! Nada obstante, é justamente quando a cidadania e os direitos dos cidadãos estão sendo ameaçados ou violados é que a figura do advogado surge como último bastião na defesa da justiça! Neste ínterim, citemos a figura emblemática de Napoleão que, quando governante demostrou seu desprezo pelos advogados e queria cortar-lhes a língua para impedir que a usassem contra seu governo. Em 1811 viu-se obrigado a restabelecer a Ordem dos Advogados na França para assegurar a boa administração da Justiça ${ }^{54}$.

Com efeito, a virtude que mais caracteriza o prestígio da profissão de advogado é a intransigente e inexorável probidade, ou honestidade - honeste vivere -, como bastião indômito às tentações que, inevitavelmente, passam todos os dias e todas as horas em frente ao advogado ${ }^{55}$. O código de ética e disciplina alcança o advogado em todas as esferas da vida, no foro, na rua, em seu escritório, isto é, em todos os espaços públicos onde seu comportamento possa repercutir no prestígio ou desprestígio da advocacia ${ }^{56}$. A função social do advogado traz em si questões de ex-

\footnotetext{
${ }^{51}$ Art. 33 do Estatuto da Advocacia e da OAB: "O advogado obriga-se a cumprir rigorosamente os deveres consignados no Código de Ética e Disciplina”. Ver também o art. 36, inciso II, do mesmo diploma legal: "A censura é aplicável nos casos de violação a preceito do Código de Ética e Disciplina".

${ }^{52}$ CARDELlA, Haroldo Paranhos. Ética Profissional da Advocacia. São Paulo: Saraiva, 2006. p. 37.

${ }^{53}$ ROBERT, Henri. O Advogado. São Paulo: Martins Fontes, 1997. p. 6.

${ }^{54}$ Ibidem. p. 31.

${ }^{55}$ LÔBO, op. cit., p. 166.

${ }^{56}$ Ibidem. p. 180.
} 
trema relevância para a sociedade e para os indivíduos. O ministério da advocacia, inclusive privado, é função indispensável para o funcionamento da justiça, conforme declara nossa Carta Magna, mas para o Estado democrático de Direito, e a luta incessante pelos direitos humanos que não podem prescindir dela. Nesta linha, até poderia ser consignado que o grau do estado democrático de um povo deve ser medido pela intensidade do respeito que se tiver pela classe dos advogados ${ }^{57}$.

À guisa se encerramento, cumpri-nos citarmos Eduardo Juan Couture, cujas linhas indicativas de atuação profissional e ética do advogado repercute mundialmente até os dias atuais. Para o grande advogado e processualista uruguaio, a advocacia é, ao mesmo tempo, arte, política, ética e ação. Como ética, a advocacia é um exercício constante e permanente da virtude, já que, pela própria característica da profissão, pelo advogado, a tentação passa sete vezes por dia, e este pode fazer de sua missão a mais nobre de todas as profissões, ou o mais vil de todos os ofícios $^{58}$.

\section{REFERÊNCIAS}

CABRAL, Sulamita Santos; VIVIANE, Karla; RECH, Nathalia. (Org.). OAB/RS: A História. Porto Alegre: Imprensa Livre, 2012.

CARDELlA, Haroldo Paranhos. Ética Profissional da Advocacia. São Paulo: Saraiva, 2006.

COUTURE, Eduardo Juan. Os Mandamentos do Advogado. Porto Alegre: Fabris, 1979.

FALLA, Fernando Garrido. Comentarios a la Constitución. $3^{\mathrm{a}}$ ed. Madrid: Civitas, 2001.

GRIMM, Dieter. Die Zukunft der Verfassung. Frankfurt am Main: Suhrkamp Taschenbuch Wissenschaft, 1991.

HESSE, Konrad. Bedeutung der Grundrechte, in: BENDA, Ernst; MAIHOFER, Werner; VOGEL, Hans-Jochen (Orgs.). Handbuch des Verfassungsrechts der Bundesrepublik Deutschland. 2a ed. Berlin-New York: de Gruyter, 1994.

LAMACHIA, Claudio Pacheco Prates; WEINMANN, Amadeu de Almeida. A História e a Vida das Prerrogativas da Advocacia. Porto Alegre: Pradense, 2012.

${ }^{57}$ Cf. LAMACHIA, Claudio Pacheco Prates; WEInMANN, Amadeu de Almeida. A História e a Vida das Prerrogativas da Advocacia. Porto Alegre: Pradense, 2012. p. 80.

${ }^{58}$ COUTURE, op. cit., p. 11. 
LÔBO, Paulo Luiz Netto. Comentários ao Estatuto da Advocacia e da OAB. $3^{\mathrm{a}}$ ed. São Paulo: Saraiva, 2002.

LYOTARD, Jean-François. A Condição Pós-Moderna. Rio de Janeiro: José Olympio, 2008.

MAMEDE, Gladston. A Advocacia e a Ordem dos Advogados do Brasil. $2^{\mathrm{a}}$ ed. São Paulo: Atlas, 2003.

MODEL CODE OF PROFESSIONAL RESPONSIBILITY - American Bar Association. Disponível em: http://www.americanbar.org. Data de acesso: 20/04/2016.

NALINI, José Renato. Ética Geral e Profissional. 12a ed. São Paulo: Editora Revista dos Tribunais, 2015.

ROBERT, Henri. O Advogado. São Paulo: Martins Fontes, 1997.

ROSENFELD, Michel. Constitutional Identity, in: ROSENFELD, Michel; SAJÓ, András (Orgs.). The Oxford Handbook of Comparative Constitutional Law. Oxford: Oxford University Press, 2012.

VIEIRA, Tereza Rodrigues; MARTINS, João Paulo Nery dos Passos. Ética no Direito. Petrópolis, RJ: Vozes, 2007. 